\title{
A implantação da ordem republicana burguesa na Manaus da borracha e o processo de legitimação da luta operária no jornal Vida Operária ${ }^{1}$
}

\author{
The implementation of a bourgeois republican order \\ in Manaus, the rubber city, and the legitimization process \\ of the working class struggle in the newspaper 'Vida Operária'
}

Luciano Everton Costa Teles ${ }^{2}$

\begin{abstract}
Resumo: $O$ presente artigo busca realizar uma reflexão acerca do espaço urbano manauara na virada do século XIX para o século XX, apresentando os mecanismos de implantação de uma ordem republicana burguesa e os impactos causados por este processo em determinados grupos, notadamente os operários. Estes últimos assimilaram alguns elementos desta ordem republicana para legitimar uma luta política em função de melhorias nas condições de vida e de trabalho.
\end{abstract}

Palavras-chave: Espaço urbano, Manaus, ordem republicana, operários, imprensa operária.
Abstract: This paper seeks to reflect upon the urban space of Manaus at the turn of the nineteenth to the twentieth century, showing the implantation mechanisms of a bourgeois republican order, as well as the impact of this process on specific groups, markedly the workers, who have assimilated some of the elements of this republican order to legitimize the political struggle for the improvement of their living and working conditions.

Keywords: Urban space, Manaus (Brazil), republican order, workers, working class press.

\section{Introdução}

O espaço urbano manauara e o das demais capitais do Brasil, sobretudo Rio de Janeiro, São Paulo e Belém, passaram por um processo de

\footnotetext{
${ }^{1} \mathrm{O}$ artigo é versão reelaborada de fragmento do capítulo 2 da dissertação de mestrado intitulada A vida operária em Manaus: imprensa e mundos do trabalho (1920), defendida em outubro de 2008 no Programa de Pós-Graduação em História da Universidade Federal do Amazonas.

${ }^{2}$ Mestre em História Social pela Universidade Federal do Amazonas. Professor assistente da Universidade do Estado do Amazonas. E-mail: lucianoeverton777@ hotmail.com
} 
transformação significativo, na virada do século XIX para o século XX, fruto da expansão econômica - no caso do sudeste, com o café, e no norte, com a borracha - e marcado por mudanças espaciais e comportamentais que causaram embates e conflitos entre os grupos que marcaram presença no interior da urbe. Com efeito, o espaço urbano presenciou disputas sociais que reverberaram nos documentos da época, em especial na imprensa diária e operária e nos documentos oficiais, tais como códigos de posturas, regulamentos sanitários, mensagens dos governadores e similares.

O objetivo deste artigo é apresentar o universo do trabalho urbano em Manaus, que foi se constituindo na virada do século XIX para o século $\mathrm{XX}$, discutindo os mecanismos de implantação de uma ordem republicana burguesa e os impactos deste processo no universo operário - revelando a apropriação, neste universo, de alguns elementos desta ordem burguesa, no sentido de utilizá-los para legitimar uma luta política visando melhorias de vida e trabalho.

\section{O universo do trabalho urbano em Manaus}

Na primeira metade do século XIX (meados de 1830 em diante), a borracha presente na Amazônia já era exportada, ainda que em quantidades modestas, para as nações industrializadas. Na chamada indústria de produtos de borracha, ela era utilizada como matéria-prima para a produção de bens industriais e bens de consumo. Entretanto, a sua utilização era limitada em virtude das influências que sofria das mudanças de temperatura. $^{3}$

Esta limitação só foi superada após o processo de vulcanização (1839), empreendido por Charles Goodyear, que tornou a goma elástica resistente ao calor e ao frio. Assim, a chamada "borracha vulcanizada" passou a ter sua utilização ampliada. Rodas dentadas, correias, mangueiras e outros produtos passaram a ser produzidos tendo-a como matéria-prima, crescimento que pode ser observado no seguinte quadro:

\footnotetext{
${ }^{3}$ A borracha possuía alta sensibilidade a mudanças de temperatura; por exemplo, "botas de borracha tornavam-se duras como pedra no inverno e grudentas como piche no verão". WEINSTEIN, Bárbara. A borracha na Amazônia: expansão e decadência (1850-1920). São Paulo: Hucitec, 1993. p. 22.
} 


\section{PRODUÇÃO DE BORRACHA NA AMAZÔNIA ENTRE 1827 E 1860}

\begin{tabular}{|c|c|c|c|}
\hline Ano & Volume $(\boldsymbol{k g})$ & Ano & Volume $(\boldsymbol{k g})$ \\
\hline $\mathbf{1 8 2 7}$ & 31.365 & $\mathbf{1 8 4 6}$ & 673.725 \\
\hline $\mathbf{1 8 3 0}$ & 156.060 & $\mathbf{1 8 5 0}$ & 1.446 .550 \\
\hline $\mathbf{1 8 3 6}$ & 189.225 & $\mathbf{1 8 5 6}$ & 1.906 .000 \\
\hline $\mathbf{1 8 4 0}$ & 388.220 & $\mathbf{1 8 6 0}$ & 2.673 .000 \\
\hline
\end{tabular}

Fonte: WEINSTEIN, Bárbara. A borracha na Amazônia: expansão e decadência (1850-1920). São Paulo: Hucitec, 1993. p. 22.

O processo de vulcanização acabou por impulsionar o consumo de borracha pelas nações industrializadas. Tal consumo se tornou ainda mais intenso com a produção e difusão da bicicleta, em 1890, e a popularização do automóvel, a partir de 1900 (sobretudo pelo desenvolvimento de pneumáticos).

Conhecida e utilizada pelos indígenas da Amazônia, a hévea torna-se produto comercial de crescente importância após a descoberta da vulcanização da borracha, em 1840. Neste período praticamente toda a borracha era extraída na área amazônica, em território brasileiro ou de países limítrofes, sendo comercializada nos portos de Manaus e Belém. [...] a borracha ganha [...] destaque em nossa pauta de exportação [Brasil] a partir de 1851-60, ocupando o terceiro lugar nela em 1881-90 e o segundo a partir de 1891 até o fim da Primeira Guerra Mundial.

A demanda da borracha nos países industrializados crescia fortemente, devido à utilização da mesma na fabricação de pneus de veículos: de bicicleta primeiro, de automóveis depois. ${ }^{4}$

4 SINGER, Paul. O Brasil no contexto do capitalismo internacional (1889-1930). In: FAUSTO, Boris. História Geral da Civilização Brasileira - v. III: o Brasil Republicano (1889-1930). São Paulo: Civilização Brasileira, 1997. p. 360-361. 
Desta forma, no decorrer do século XIX, sobretudo a partir das três últimas décadas, a Amazônia foi incorporada ao mercado mundial articulado. Neste sentido, como aponta Paul Singer na passagem anteriormente citada, duas cidades tornaram-se centros comerciais: Belém e Manaus.

No Amazonas, o processo de expansão econômica trouxe consigo um conjunto de transformações que atingiram sua capital, Manaus. Neste processo de expansão, dois elementos foram de profunda importância: a implantação de uma rede de comercialização da borracha e o desenvolvimento de uma infraestrutura necessária para o escoamento do produto.

Com relação ao primeiro elemento, o que interessa destacar é a atuação das casas aviadoras. Conhecidas também como "casas recebedoras", possuíam uma posição central na cadeia comercial da Amazônia. Eram estes estabelecimentos que tinham a função de financiar e comercializar a borracha, decidindo inclusive quando e a quem vender este produto extrativo. Além disso, assumiam múltiplas funções: negociavam, com as casas importadoras, as mercadorias que seriam passadas para o negociante do vilarejo, ao regatão, ao seringalista e por fim ao seringueiro; providenciavam o transporte e a distribuição dos retirantes que se deslocavam do Nordeste, fugindo dos problemas gerados pela seca, em busca de trabalho no Amazonas (seringais); atuavam como representantes legais e financeiros de seus clientes mais ricos que residiam no interior e, por fim, realizavam a abertura de novos seringais. ${ }^{5}$

O papel desempenhado por esses estabelecimentos comerciais foi o de financiar e comercializar a borracha na região, fazendo chegar os implementos necessários à organização e funcionamento da vida econômica dos seringais, bem como recebendo deles, no final do período de extração, as remessas de borracha que, posteriormente seriam exportadas para a Europa e Estados Unidos. ${ }^{6}$

Como a borracha se mostrou um empreendimento rendoso, o capital estrangeiro passou a atuar na região com objetivo de viabilizar a exploração

\footnotetext{
${ }^{5}$ WEINSTEIN. A borracha na Amazônia..., op.cit., p. 33-34.

${ }^{6}$ PINHEIRO, Maria Luiza Ugarte. A cidade sobre os ombros: trabalho e conflito no Porto de Manaus (1899-1925). Manaus: Edua, 1999. p. 37.
} 
do produto, contribuindo desta forma não só para a reconstrução/revitalização da cadeia comercial desenvolvida na Amazônia, ancorada no sistema de aviamento, como também para a construção, na cidade de Manaus, de uma infraestrutura que possibilitasse o escoamento do produto.

Neste ponto reside o segundo elemento de expansão econômica: a infraestrutura era importante para o escoamento da produção, facilitando a circulação de pessoas e capitais. Como a produção da borracha se dava fora do espaço urbano (nos seringais), a cidade se colocava como ponto de escoamento deste produto, daí a necessidade de criar uma gama de atividades econômicas ligadas à circulação, consumo e serviços (transportes, limpeza pública, água, luz, esgoto).

Desta forma, o capital estrangeiro, sobretudo inglês, tornou-se o maior responsável pela execução dos grandes projetos de reforma da cidade, ${ }^{7}$ realizados, sobretudo na última década do século XIX e nos anos iniciais do século XX. Conforme Pinheiro, praticamente todos os serviços urbanos, por concessão, estavam nas mãos de firmas inglesas que passaram a agenciar melhoramentos ou mesmo criar serviços até então inexistentes na cidade. Empresas como a Manáos Markets, Manáos Tramways and Light, Manáos Improvements, Manáos Harbour, Amazon Engineering, Amazon Telegraph, Booth Line e Amazon River ${ }^{8}$ passaram a manter relações cotidianas com a população local. ${ }^{9}$

A cidade de Manaus passou a assumir a função de centro comercial. Diversas atividades, em grande medida moldadas pela posição econômica assumida pela cidade, foram desenvolvidas no interior do espaço urbano. Além das firmas estrangeiras que atuavam na administração dos serviços urbanos (porto, transporte, energia, abastecimento de água etc.) ocorreu uma ampliação significativa da praça comercial nos anos iniciais do século XX. Diversos estabelecimentos comerciais passaram a comercializar uma variedade de produtos nacionais e importados, assim como uma gama variada de serviços (hotéis, restaurantes, botequins etc.) começou a ser oferecida na cidade. Além disso, a cidade passou a presenciar o surgimento de marcenarias, sapatarias, alfaiatarias, fábricas de tecido, fábricas de roupas, fábricas de cestas e vassouras, funilarias, tabacarias, fábricas de

\footnotetext{
7 DIAS, Ednéa Mascarenhas. A ilusão do fausto: Manaus, 1890-1920. Manaus: Editora Valer, 1999. p. 50.

8 Em geral, estas empresas passaram a atuar em Manaus nos anos finais do século XIX e início do século XX. Ver: DIAS Ednéa Mascarenhas. A ilusão do fausto... op. cit. p. 69-92.

${ }^{9}$ PINHEIRO. A cidade sobre os ombros..,, op. cit. p. 42.
} 
panificação, fábrica de cerveja e gelo, fábrica de sabão e outros. ${ }^{10}$ Enfim, os ramos econômicos desenvolvidos tinham como alicerces as atividades de circulação e consumo, havendo a atuação, em pequena escala, de oficinas/fábricas específicas. Com efeito, a ampliação do mercado de trabalho manauara se deu ancorada nestas bases.

Cabe lembrar também que a imigração foi essencial para a ampliação das atividades acima destacadas. A partir do final do século XIX, Manaus passou a recepcionar uma onda imigratória crescente. Um número significativo de pessoas, entre estrangeiros e nacionais, acabou por chegar ao universo urbano e a disputar espaços de trabalho nas mais diferentes atividades. Este processo se intensificou ainda mais a partir do aumento das exportações da goma elástica. Segundo Dias:

É no decorrer desse processo [de expansão econômica] que Manaus passa a vivenciar a ampliação e remodelação de seu espaço, assim como o aumento de sua população. Se em 1852 a cidade contava com uma população de 8.500 habitantes, em 1890 já tem sua população ampliada para 50.300, sendo o processo migratório o principal responsável por este crescimento populacional. O centro urbano se constitui como polo de atração de gente das mais diversas nacionalidades: ingleses, alemãs, portugueses, espanhóis, italianos, franceses, deslocam-se para cá, como também imigrantes de vários estados do país. ${ }^{11}$

Assim, a ampliação do mercado de trabalho manauara se deu em virtude da expansão econômica associada ao crescimento populacional.

\section{Manaus e a implantação da ordem republicana burguesa}

A acumulação de capital proporcionada pela exportação do látex produziu, por volta de 1890, um processo de modernização e urbanização na capital do Amazonas. Produziu também o deslocamento de um conjunto significativo de pessoas tanto do estrangeiro quanto das demais regiões

\footnotetext{
${ }^{10}$ COSTA, Francisca Deusa Sena da. Quando viver ameaça a ordem urbana: cotidiano de trabalhadores em Manaus, 1915-1925. São Paulo, 2000. Dissertação de Mestrado. PUC-SP. p. 53.

${ }^{11}$ DIAS. A ilusão do fausto..., op. cit. p. 38.
} 
brasileiras (sobretudo do Nordeste) que, atraídas pelas propagandas institucionais acerca das potencialidades econômicas da região, ${ }^{12}$ passaram a se fazer presentes na cidade.

Por conta disso, a elite política e econômica desenvolveu um conjunto de ações em torno de dois eixos principais: o próprio espaço urbano e as relações nele desenvolvidas. No que tange ao primeiro eixo, ocorreu uma intervenção cirúrgica visando à adaptação do espaço urbano às exigências econômicas e sociais surgidas neste momento (são as obras de infraestrutura e a implantação dos serviços urbanos). Estas intervenções nortearam a ocupação de novas áreas e definiram os rumos da expansão urbana, com destaque para os padrões de edificação (prédios e casas construídos com fachadas padronizadas) e de arruamento (ruas largas com traçado em ângulos perpendiculares de 90 graus). ${ }^{13}$

A reordenação da espacialidade urbana veio acompanhada de um conjunto de regras de condutas que pretendiam eliminar os comportamentos e hábitos classificados, a partir de então, como indesejáveis. Neste ponto se encontra o segundo eixo das ações:

Em lei promulgada em julho de 1893, ficavam proibidas dentro de "determinado perímetro da cidade" as hortas, capinzais e cocheiras e eram autorizadas por lei a colocação de placas de denominação das ruas e a numeração das casas. Eram inúmeras as medidas que promoviam a regularização e o controle do espaço da cidade, racionalizando seus usos e expulsando do perímetro urbano comportamentos indesejáveis que viessem a macular a imagem de "progresso" pretendida. $^{14}$

\footnotetext{
${ }^{12}$ Maior exemplo neste sentido é o álbum sobre a região de Barão de Santa-Anna Nery, publicado em 1901, divulgado e distribuído por diversas regiões do globo. Ver: DAOU, Ana Maria. A cidade, o teatro e o país das seringueiras: práticas e representações da sociedade amazonense na virada do século XIX. Rio de Janeiro, 1998. Tese de Doutorado. Universidade Federal do Rio de Janeiro. p. 205-212.

${ }^{13}$ Cabe lembrar que as transformações ocorreram nas áreas comerciais e seus entornos. Desta forma, podem-se destacar dois polos irradiadores: a Avenida Eduardo Ribeiro e a Rua Municipal. Consoante Costa, as normatizações das posturas faziam-se presentes nesses dois polos e nas vias secundárias em redor. COSTA, Francisca Deusa Sena da. Quando viver ameaça a ordem urbana, 1900-1915. In: FENELON, Dea Ribeiro. Cidades: pesquisa em História. São Paulo: Olho D’Água, 2000. v.1, p. 95.

${ }^{14}$ DAOU. A cidade, o teatro e o país das seringueiras..., op.cit. p. 193.
} 
Os códigos de posturas produzidos neste momento eram os instrumentos por excelência a impor as regras de condutas e o uso racional do espaço. Porém, a atuação dos populares, sobretudo dos operários, contrariaria as regras impostas pelos setores dirigentes, conforme será comentado adiante.

Além disso, as demandas por emprego e serviços na cidade foram superiores à capacidade de absorção do mercado de trabalho, o que produziu um contingente de desempregados, carentes e marginais. Estes excluídos do látex acabaram por desenvolver no espaço urbano estratégias de sobrevivência diversas, ${ }^{15}$ que também caminhavam na contramão da cidade idealizada pela elite local.

Assim, a exclusão social, presente no bojo das transformações socioeconômicas que ocorreram no final do século XIX e início do século $\mathrm{XX}$ em algumas das principais capitais da Primeira República brasileira, gerou um processo conflitivo entre grupos sociais.

Com efeito, em Fortaleza, em função das atividades ligadas à produção de algodão e criação de gado, as transformações urbanas foram operadas pelo poder público e norteadas pela imposição/adoção de condutas e etiquetas tidas como "civilizadas". "De acordo com técnicas de planejamento do espaço físico e social, desenharam-se correções, coações, normatizações que agiram mapeando Fortaleza". ${ }^{16}$

Considerando exemplos mais específicos, no Rio de Janeiro, a moradia popular - cortiços, estalagens e similares - foi cedendo espaço às grandes avenidas e edificações sofisticadas construídas pelos grupos abastados, assim como determinadas práticas sociais, como a capoeira, foram perseguidas, neste processo de transformações urbanas, por não estarem alinhadas às normas e ao comportamento tidos como "modernos". Neste sentido, uma parcela significativa da população negra teve que se deslocar para locais distantes da área central para sobreviver. Este processo contribuiu para a emergência da ideia de duas cidades, uma europeizada (padrões de conduta e sociabilidade tidos como "modernos"), outra

\footnotetext{
${ }^{15}$ São elas o roubo, o furto, a gatunagem, a mendicância, a venda ambulante, dentre outras. Ver: MARREIRO JÚNIOR, Paulo dos Santos. Criminalidade e criminalização de práticas populares em Manaus, 1906-1917. São Paulo, 2006. Dissertação de Mestrado. PUC-SP.

16 BARBOSA. Entre casas de palha e jardins: Fortaleza nas primeiras décadas do século XX. In: FENELON (org.). Cidades..., op.cit. p. 158.
} 
quilombada. ${ }^{17}$ Desta forma, percebe-se que a "exclusão social" opera-se por meio de parâmetros sociais e econômicos e nem sempre num sentido total. ${ }^{18}$

Ainda considerando o mesmo contexto carioca, Menezes destacou algumas das ações desenvolvidas por grupos presentes tanto no mundo do trabalho quanto por aqueles que viviam a sua margem, e que eram vistas pelos setores dirigentes como desordem urbana. Assim, os "desordeiros" eram aqueles que

[...] por palavras ou ações, voltavam-se contra a ordem política, econômica, moral e social existentes, considerados nocivos à sociedade e perigosos à segurança pública - regra geral, aqueles que, por meios variados, contestavam a propriedade, o trabalho, a família, a moral cristã e os poderes constituídos, apresentando-se como desviantes aos padrões de comportamento socialmente aceitos - desordeiros, na apreensão global do termo. ${ }^{19}$

Além do Rio de Janeiro e Fortaleza, São Paulo, ${ }^{20}$ Porto Alegre, ${ }^{21}$ Belém $^{22}$ e outras capitais do Brasil presenciaram, ao longo da Primeira República brasileira, cada uma a seu modo, embates e conflitos desenvolvidos no interior do espaço urbano por grupos sociais que aí se relacionavam. Não resta dúvida de que o espaço urbano se caracterizou então como palco principal das contradições e conflitos desenvolvidos.

Embora com as marcas das especificidades locais, em Manaus não foi diferente. Filhos da expansão da economia gomífera e de seus

\footnotetext{
${ }^{17}$ Embora fossem percebidas desta forma pelos grupos que formavam a elite carioca, estas "duas cidades" estavam em constante interação. NEDER, Gizlene. Cidade, identidade e exclusão social. Tempo, Rio de Janeiro, n. 3, 1997.

18 Isto porque os setores populares, alvos das pressões sociais e econômicas, imprimiram resistências ao processo de modernização das cidades, ora permanecendo nas áreas centrais, ora perpetuando suas práticas sociais e culturais.

19 MENEZES, Lená Medeiros de. Os indesejáveis: desclassificados da modernidade protesto, crime e expulsão na Capital Federal (1890-1930). Rio de Janeiro: EDUERJ, 1996. p. 91.

${ }^{20}$ HAHNER, June. Pobreza e política: os pobres urbanos no Brasil, 1870-1920. Brasília: EDUNB, 1993.

${ }^{21}$ PESAVENTO, Sandra Jatahy. Uma outra cidade: o mundo dos excluídos no final do século XIX. São Paulo: Cia Editora Nacional, 2001.

${ }^{22}$ SARGES, Maria de Nazaré. Um outro olhar sobre a "Paris dos Trópicos" (1897-1911). In: SOLLER, Maria Angélica, MATOS, Maria Izilda. A cidade em debate. São Paulo: Olho D’água, 2001. p. 49-73.
} 
desdobramentos, com destaque para a urbanização e modernização, as contradições, os embates e os conflitos não só fizeram-se presentes no espaço urbano manauara como também o transformaram em palco de disputas sociais. Estas disputas se materializaram nas questões referentes a moradia, saúde, lazer e trabalho.

No bojo dessas disputas sociais, uma questão se apresentou como fundamental: a organização do trabalho. Cabe destacar que esta era uma questão de âmbito nacional e remontava à transição do trabalho escravo para o trabalho livre. Neste período, nas principais capitais do Brasil esta questão estava na ordem do dia, como afirma Gizlene Neder:

A modernização das cidades [...] constitui, contudo, um dos aspectos do processo histórico de passagem ao capitalismo que envolve, na virada do século XIX para o século XX, o aprofundamento do aburguesamento, com a implantação do regime republicano. Neste contexto, deve-se considerar a passagem do regime de trabalho escravo para o trabalho livre e seus desdobramentos no tocante às formas históricas de controle social definidora dos marcos de exclusão social que se vão imprimindo na cidade. ${ }^{23}$

No Brasil, a implantação do regime republicano veio acompanhada da necessidade de organização do trabalho livre. Para os grupos que compunham as elites políticas e econômicas, era necessário elaborar, desenvolver e implantar mecanismos de disciplina e controle que garantissem ao mesmo tempo a presença do trabalhador no espaço de trabalho e uma significativa produtividade. Neste sentido, a construção da noção de vadiagem e o desenvolvimento de um aparato jurídico-policial tiveram papel preponderante.

No que tange à primeira assertiva, nota-se que a construção da noção de vadiagem está intimamente associada à elaboração e difusão de uma nova ética do trabalho. Segundo Chalhoub, em 1888, ainda no período imperial, foi apreciado na Câmara dos Deputados um projeto de repressão à ociosidade, de autoria do ministro Ferreira Vianna. Este projeto foi motivado pela abolição da escravatura, sobretudo porque ela significava "uma ameaça à ordem, porque nivelava todas as classes de um dia para o

\footnotetext{
${ }^{23}$ NEDER, Gizlene. Cidade, identidade e exclusão social. Tempo, Rio de Janeiro, n. 3, 1997, p. 111.
} 
outro, provocando um deslocamento de profissões e de hábitos de consequências imprevisíveis". ${ }^{24}$

O projeto de combate à ociosidade produziu no Parlamento inúmeras discussões acerca do trabalho e do trabalhador. Produziu também um consenso: com o término da escravidão, a ordem estava ameaçada. Este sentimento acabou se refletindo no Código Penal de 1890, que definiu a vadiagem como um delito de grande amplitude. Por meio deste instrumento, a vadiagem era definida como:

Deixar de exercitar profissão, ofício ou qualquer mister em que ganhe a vida, não possuindo meios de subsistência e domicílio certo em que habite; prover a subsistência por meio de ocupação proibida por lei, ou manifestamente ofensiva da moral e dos bons costumes. $^{25}$

Não resta dúvida que a noção de vadiagem foi construída tendo como contraponto a construção da valorização do trabalho. $\mathrm{O}$ trabalho, considerado outrora como aviltante e degradante em função da sua vinculação com a escravidão, era agora elevado ao patamar de ordenador da sociedade, visto como elemento essencial para a produção de riquezas. Como valor social supremo da modernidade, o trabalho era fundamental para a sociedade e o indivíduo.

Com efeito, no Código de Posturas de Manaus (1890) esta questão apareceu sob a forma de pressão sobre aqueles que estavam sem trabalho.

$\mathrm{O}$ indivíduo que viver sem indústria, emprego ou profissão habitual certa, honesta e suficiente é considerado vadio e vagabundo e como tal obrigado, desde que for intimado pelo Fiscal, a tomar uma ocupação honesta dentro de 15 dias e no fim desse tempo deve provar ter tomado um emprego ou ocupação que lhe garanta a subsistência. ${ }^{26}$

\footnotetext{
${ }^{24}$ CHALHOUB, Sidney. Trabalho, lar e botequim: o cotidiano dos trabalhadores no Rio de Janeiro da Belle Époque. São Paulo: UNICAMP, 1991. p. 67.

${ }^{25}$ Código Penal dos Estados Unidos do Brazil [Cap. XIII, art. 399]. Collecção de Atos do Governo Provisório. Rio de Janeiro: Imprensa Nacional, 1891.

${ }^{26}$ Citado por DIAS. A ilusão do fausto..., op. cit.. p. 33.
} 
Portanto, percebe-se a preocupação em forçar, por meio de um instrumento específico, as pessoas sem trabalho a procurá-lo o mais brevemente possível, sob pena de serem consideradas vadias.

Em geral, a consideração da vadiagem (o não trabalho) como contravenção se assentou na ideia de que ela se configurava como précondição para o crime. Deste modo, abarcava em seu universo várias contravenções, o que permitiu englobar "num só conjunto [...] tanto mendigos, bêbados e desocupados" quanto gatunos, falsários e vigaristas, o que demonstra sua grande amplitude. ${ }^{27}$

Com efeito, a ideia de vadio não somente contribuiu significativamente para a elaboração de um aparato jurídico-policial como nele se fez presente. É possível perceber este fato a partir do processo de reordenação do espaço urbano ocorrido em Manaus no período em questão. Este processo trouxe, em seu bojo, um conjunto de leis que passaram a nortear inclusive a ação policial, no sentido de moldar padrões de conduta e comportamentos desejáveis. Com base nos relatórios da chefatura de polícia e nas mensagens dos governadores a respeito da segurança pública em Manaus, é possível perceber na ação policial um "caráter inibidorrepressivo", o que contribuiu significativamente para a construção de uma fronteira separando o "mundo da ordem" (do trabalho) do "mundo da desordem" (do não trabalho). ${ }^{28}$

Com efeito, desenvolveu-se a partir de então uma fiscalização e vigilância daquilo que seria considerado "desvio de conduta" ou "comportamento indesejável". Em mensagem lida perante o Legislativo Estadual, por ocasião da abertura da primeira sessão ordinária da sétima legislatura, em 10 de julho de 1910, o governador do Estado, Antônio Clemente Ribeiro Bittencourt, apresentou algumas informações sobre os delitos criminosos em Manaus. Tais informações identificavam a época do ano em que os delitos ocorriam com maior intensidade, a sua natureza e causas sociais. Quanto às duas últimas questões, os crimes eram considerados "de natureza leve", tendo como "causas principaes" o "alccolismo e a prostituição". Apontava ainda a mensagem que, "de 381 prisões effectuadas de janeiro a maio", todas haviam sido causadas "por

\footnotetext{
${ }^{27}$ MENEZES. Os indesejáveis..., op.cit. p. 132.

${ }^{28}$ A ideia do mundo da ordem, ligado à organização do trabalho, e do mundo da desordem, como o mundo do não trabalho, foi retirada de NEDER. Cidade, identidade e exclusão social..., op. cit. p.106-134.
} 
embriaguez", e finalizava condenando o jogo, o alcoolismo e a prostituição. $^{29}$

No relatório do Chefe de Segurança Pública de Manaus, a embriaguez, os distúrbios, as algazarras, as desordens, a vadiagem, a gatunagem e os pequenos furtos eram os delitos mencionados nos anos iniciais do século XX. ${ }^{30}$ Desta forma, práticas como jogo, prostituição, uso de bebida alcoólica, elementos vistos como integrantes do "mundo da desordem", foram focalizadas e condenadas pelo poder público e pelos jornais da imprensa diária, que se esforçavam em desqualificá-las construindo imagens estereotipadas daqueles que nelas estavam inseridos (como os operários).

Ao tratar dos operários na cidade de São Paulo na Primeira República brasileira, Decca apontou que:

Os meios operários eram vistos por instituições e grupos dirigentes como extremamente perniciosos para a "moral e disciplina do trabalho", focos de agitação e revolta social. Hábitos operários no escasso tempo de lazer eram considerados vícios, e a recreação do operariado era considerada "improdutiva".

Inseridas no quadro de delitos presente no relatório da Chefatura de Polícia, as práticas ligadas ao lazer operário eram vistas como comprometedoras da "capacidade de trabalho". ${ }^{32}$ Desta forma, é possível entender a solução apresentada pela mensagem do Executivo anteriormente citada, que em outra passagem destacava a construção e funcionamento de espaços que promovessem a educação (e neste aspecto a tentativa de se

\footnotetext{
${ }^{29}$ Mensagem lida perante o Congresso dos Representantes por occasião da abertura da primeira sessão ordinária da sétima legislatura, em 10 de julho de 1910, pelo Exm.Sr. Governador do Estado, Cel. Antônio Clemente Ribeiro Bittencourt, acompanhada dos relatórios dos chefes das repartições. Manáos: Seção de Obras da Imprensa Oficial, 1911. 30 Relatório do Chefe de Segurança Pública, contido em: Mensagem lida perante o Congresso dos Representantes por occasião da abertura da $1^{\mathrm{a}}$. sessão ordinária da $5^{\mathrm{a}}$. legislatura pelo Governador do Estado Exm.Sr. Dr. Silvério José Nery, em 10 de julho de 1904, acompanhada dos relatórios dos chefes das repartições do Estado. Manáos: Typographia do Amazonas, 1905. [Nota da editora de Fronteiras: as citações extraídas diretamente de documentos produzidos no período analisado não foram modernizadas.]

${ }^{31}$ DECCA, Maria Auxiliadora Guzzo de. A vida fora das fábricas: cotidiano operário em São Paulo (1920-1934). Rio de Janeiro: Paz e Terra, 1987. p. 89.

32 Relatório da Chefatura de Polícia do Estado do Amazonas, contido em: Mensagem lida perante o Congresso dos Representantes... [10 de julho de 1904], op.cit.
} 
construir uma ética do trabalho) e a vida em família. ${ }^{33}$ Portanto, pelo menos dois aspectos do cotidiano operário eram alvos de preocupação e controle para os grupos dirigentes de Manaus: o lazer e a moradia.

Essas duas esferas privadas do cotidiano operário foram objeto de discussões e debates entre os setores dirigentes, girando em torno da criação de padrões de conduta e comportamento que viabilizassem maior vigor para o trabalho. Pensadas como extensão do espaço de trabalho, estas esferas tinham que proporcionar ao operário a renovação de sua capacidade produtiva.

Com relação à moradia no Rio de Janeiro no início do século XX, Margareth Rago, ao procurar entender o processo de formação da família nuclear moderna e os mecanismos de controle da família operária, destacou que

A habitação [...] não escapará ao desejo de disciplinarização do proletariado manifesto pelos dominantes. Na moradia operária, a burguesia [...], os higienistas e os poderes públicos visualizam a possibilidade de instaurar uma nova gestão da vida do trabalhador pobre e controlar a totalidade de seus atos, ao reorganizar a fina rede de relações cotidianas que se estabelecem no bairro [...], na casa e, dentro desta, em cada compartimento. Destilando o gosto pela intimidade confortável do lar, a invasão da habitação popular pelo olhar vigilante e pelo olfato atento do poder assinala a intenção de instaurar a família nuclear moderna, privativa e higiênica, nos setores sociais oprimidos. ${ }^{34}$

A tentativa de "reorganizar a fina rede de relações cotidianas" se fez presente também na esfera do lazer. Procurando desenvolver atividades de lazer que fossem ao encontro dos valores presentes no mundo do trabalho (como a competitividade e a disciplina), o poder público buscou associá-los e torná-los constantes no dia a dia operário.

\footnotetext{
${ }^{33}$ Mensagem lida perante o Congresso dos Representantes...[10 de julho de 1910], op.cit.. p. 33.

${ }^{34}$ RAGO, Margareth. Do cabaré ao lar: a utopia da cidade disciplinar, Brasil (1890-1930). Rio de Janeiro: Paz e Terra, 1985. p. 163.
} 


\section{Valorização do trabalho e do trabalhador em Manaus: ordem republicana burguesa e legitimação da luta operária no jornal Vida Operária}

Em Manaus, na virada do século XIX para o século XX, a expansão econômica e o crescimento populacional contribuíram para a ampliação do mercado de trabalho urbano. Neste momento, era fundamental para os grupos econômicos e o poder público a organização do universo do trabalho. Na implantação da ordem republicana e burguesa, mecanismos foram criados não somente para viabilizá-la como também para organizar o trabalho.

Desta forma, o espaço urbano de Manaus sofreu transformações na sua estrutura física e na forma de utilizar essa nova estrutura, ou seja, na conduta de seus habitantes, que tinham que se comportar a partir de referências tidas como "modernas". Caso caminhassem na contramão da ordem almejada, poderiam se tornar "indesejáveis" e sofrer as consequências que o Código de Posturas estabelecia.

Imersos neste processo, os operários buscavam superar dificuldades relacionadas às condições de trabalho e de vida. Entretanto, tinham que agir sem serem acusados de "indesejáveis" e "desordeiros". Para compreender esta ação, o jornal Vida Operária foi fundamental, por se direcionar aos operários e por incorporar questões ligadas ao universo operário. ${ }^{35}$

O jornal Vida Operária passou a circular em Manaus em 8 de fevereiro de 1920. Foram 26 números publicados, sendo o último no dia 26 de setembro do mesmo ano.

Em seu primeiro número, em artigo intitulado Como surgimos, o jornal registra o espaço em que foi idealizado, quem o idealizou e como, enfim, surgiu. Assim, numa espécie de "bohemia espiritualizada", em torno de uma banca de mármore (provavelmente em algum botequim), entre tragos de cigarro e café, cinco indivíduos - Elesbão Luz, Oswaldo Mário, Hemetério Cabrinha, Anacleto Reis e Nicodemos Pacheco - interessados na ideia de fundar um jornal operário, o conceberam.

\footnotetext{
${ }^{35}$ O jornal Vida Operária não era produzido por operários, mas era direcionado a este grupo. Ver: FERREIRA, Maria Nazareth. Imprensa operária no Brasil. São Paulo: Ática, 1988. p.13-14.
} 
Sim a Vida Operária...

Responde o Velho professor.

Surgirá! Exclama Oswaldo enthusiasmado!

E brilhará! Murmura Cabrinha agitado, dizendo: o Luz será o diretor!

E a parte litterária é sua! exclama Oswaldo. Irrevogável! Pois você é o sucurijú da prosa e a águia do verso!

E é logo alli sobre a mudez impenetrável do mármore que se idealiza o artigo de fundo... a vida mundana... o programma...

Nada! Diz o Cabrinha com os dedos entre os cabellos desalinhados. Há de ser assim...

E já a passarada celebrava os funeraes do sol, quando dalli sahimos intoxicados de jornalismo, e de ideas grandes.

E foi assim que surgimos! $!^{36}$

Nas duas primeiras páginas eram distribuídos os artigos e as notícias. Na análise da distribuição de ambos, percebeu-se a existência de dois eixos principais no discurso do jornal. O primeiro, ligado à elaboração de críticas ao sistema capitalista e sua atuação exploradora e opressora sobre o operário. $\mathrm{O}$ segundo, associado à orientação para uma determinada ação operária, no sentido de se obter uma mudança social.

Os desdobramentos que surgiam a partir daí traziam como questões a importância de um veículo de comunicação para a discussão e difusão de ideias, as desigualdades sociais presentes no mundo moderno, a situação política do operariado amazonense, a ação operária a ser seguida, a organização dos trabalhadores em associações, a fundação de um partido operário, a importância do processo político-eleitoral e denúncias sobre questões do trabalho (acidentes de trabalho, demissões arbitrárias, multas e penalidades) e da vida (carestia dos gêneros de primeira necessidade, alcoolismo, jogatina e outros).

As matérias veiculadas nas páginas do jornal eram assinadas por diversas pessoas, como demonstra o quadro seguinte:

\footnotetext{
${ }^{36}$ Vida Operária, Manaus, n. 1, 8 fev. 1920. Optou-se por não modernizar as citações do periódico, mantendo a ortografia então adotada.
} 


\section{AUTORES PRESENTES NO JORNAL VIDA OPERÁRIA}

\begin{tabular}{|c|c|c|}
\hline Autores & $\operatorname{Artigo(s)}$ & $\begin{array}{c}\text { Edição } \\
\text { do jornal }\end{array}$ \\
\hline Arnaldo de Barcellos & Reportagens oportunas & n. 16 \\
\hline Benjamin de Araújo Lima & Aos operários do Amazonas & n. 23 \\
\hline Cleomenes Honório Dias & O que é o operariado & n. 26 \\
\hline Cursino Gama & O momento & n.9 \\
\hline Elesbão Luz & Sem comentários & n.13 \\
\hline \multirow{2}{*}{ Flávio Remar } & Operariado & n. 2 \\
\hline & A carestia da vida & n.3 \\
\hline Fulton & $\begin{array}{l}\text { O dia } 14 \text { de Julho e a eleição } \\
\text { governamental do Amazonas }\end{array}$ & n.21 \\
\hline \multirow{2}{*}{ Guilherme de Oliveira } & Aurora promissora & n.1 \\
\hline & Outro rumo & n.6 \\
\hline Hemetério Cabrinha & Está na hora & n.13 \\
\hline J. Pimenta & Finanças da Vida Operária & n. 18 \\
\hline \multirow{2}{*}{ João do Monte } & Collaboração & n. 2 \\
\hline & A postos & n. 4 \\
\hline Maia Filho & $\begin{array}{l}\text { Operariado amazonense e as demais } \\
\text { classes trabalhadoras do Amazonas }\end{array}$ & n. 17 \\
\hline Manoel Sérvulo & Palavras simples & n.6 \\
\hline Mauro Santos & Amor e Trabalho & n. 25 \\
\hline Nicodemos Pacheco & Bilhete aos reaccionários & n. 20 \\
\hline Oswaldo Mário & Como surgimos & n. 1 \\
\hline Plínio & $\begin{array}{l}\text { O Sr. Camilo Prates em luta } \\
\text { contra o operariado nacional }\end{array}$ & n. 23 \\
\hline Rita da Conceição Alves & O Dia do Trabalho & n. 14 e $n .15$ \\
\hline \multirow{2}{*}{ Salustino Liberato } & Não se illudam & n.12 \\
\hline & União e Coragem & n.16 \\
\hline Santos Filho & Aproxima-se & n. 4 \\
\hline Venicius & $\begin{array}{l}\text { O futuro governo e as demais forças } \\
\text { vivas do Estado }\end{array}$ & n. 19 \\
\hline
\end{tabular}

Fonte: Jornal Vida Operária (n.1 ao n.26) 
Nomes como Guilherme de Oliveira, Manoel Sérvulo, Cursino Gama, Nicodemos Pacheco, Hemetério Cabrinha, Elesbão Luz, Oswaldo Mário, Flávio Remar e J. Pimenta apareciam ligados a sociedades operárias (Sindicato dos Cigarreiros, Centro Operário, União Operária e outros). Porém, percebe-se que, em momentos tidos como especiais, notadamente o $1^{\circ}$. de maio e as eleições, outras vozes se colocavam, como a da professora da Escola de Aprendizes-Artífices Rita da Conceição Alves, falando sobre o $1^{\circ}$. de maio de 1920, e as de Maia Filho, Fulton e Venicius, tratando das eleições governamentais. Existiam ainda artigos que não eram assinados.

É importante destacar a constante presença, no cenário político amazonense, de nomes como Nicodemos Pacheco, Elesbão Luz, Anacleto Reis e Cursino Gama. Para citar um exemplo desta presença: em 1919 ocorreu uma "greve geral" em favor da jornada de oito horas de trabalho, alvo de manifestações em nível nacional. Em Manaus foi formado o Comitê de Operários Amazonenses para conduzir a greve. Este comitê era composto pelos senhores acima citados, sendo que Nicodemos Pacheco era seu presidente. $^{37}$

Mesmo após a greve de 1919 ter sido sufocada pela repressão e o Comitê extinto e expulso do seu local de funcionamento, este grupo parecia não desistir de lutar em prol da melhoria das condições de trabalho e de vida da classe operária, como demonstra a sua presença na elaboração, produção e difusão do jornal Vida Operária e, após o desaparecimento deste, no jornal "comemorativo" denominado $1^{o}$. de maio (1928), cujo diretor era Cursino Gama.

O jornal Vida Operária era distribuído em espaços restritos, como associações, colégios, institutos, e nos bares e botequins. Dentre as associações estavam a União Operária Nacional, o Centro Operário Nacional, a Associação de Classe das Quatro Artes da Construção Civil, a Sociedade Beneficente União dos Foguistas, o Sindicato dos Estivadores, a Associação de Trabalhadores de Artes Gráficas, a União dos Moços e Marinheiros, a União de Classe dos Pedreiros, o Sindicato dos Cigarreiros, a Associação dos Construtores Civis e, por fim, a Coligação dos Oficiais da Marinha Mercante.

Focar o jornal Vida Operária possibilitou compreender como os editores e colaboradores do jornal se apropriaram de elementos presentes na implantação da ordem burguesa para a promoção de uma luta

${ }^{37}$ PINHEIRO. A cidade sobre os ombros.., op. cit. p.172-173. 
política. ${ }^{38}$ Neste sentido, o jogo era uma prática condenada no referido jornal:

Campeia livremente até altas horas da noite, em diversos pontos desta cidade, o cancro social - o jogo onde centenas de pessoas vão deixar o dinheiro que ganharam durante o dia com mil sacrifícios.

A maior parte das vezes, infelizes operários, atrahidos por esse maldito quino, perdem o último vintém, e no dia seguinte, as suas famílias ficam entregues aos negrumes da fome.

Além de tudo esses antros perniciosos convertem os habitués em alcoólatras inveterados, maus cidadãos e maus chefes de família.

Terminando, pedimos em nome do operariado enérgicas providências ao exmo. Snr. Desembargador Raposo da Câmara, d. d. chefe de polícia, para que ponha termo a essa jogatina desenfreada. ${ }^{39}$

Percebe-se que, no artigo extraído do jornal, o álcool é mencionado. A bebida alcoólica, da mesma forma que o jogo, era contestada nas páginas do Vida Operária:

Outro vício não menos pernicioso é o álcool, que já contaminou quase todos os habitantes da terra [...] apellamos para a Assembleia Legislativa do Estado que se acha em trabalhos, para que nos dê leis, que cohiba o álcool, o jogo, a prostituição e alguma cousa mais. ${ }^{40}$

Como se pode notar, o conteúdo presente nos dois artigos publicados é o mesmo presente nos discursos produzidos e difundidos pelos

\footnotetext{
${ }^{38}$ No jornal Vida Operária, a proposta política defendida e difundida pelo jornal apontava para a fundação de Associações Operárias ligadas a um Centro Federativo (cada Estado da Federação teria o seu). Este Centro se ligaria à Confederação do Trabalho, cuja sede seria na Capital Federal. O Partido Operário estaria ligado ao Centro Federativo e teria âmbito nacional. $\mathrm{O}$ objetivo era articular os operários em associações ligadas a um Centro, que por sua vez estaria articulado ao Partido Operário; o Partido Operário se empenharia em lançar nomes para participar do processo político-eleitoral, a fim de eleger representantes que atuariam no sentido de realizar, via legislação, as reformas sociais.

${ }^{39}$ Vida Operária, Manaus, n. 21, 25 jul. 1920.

${ }^{40}$ Vida Operária, Manaus, n.22, 8 ago. 1920.
} 
setores dirigentes sobre aquilo que se constituem práticas do lazer operário. E mais, ainda são pedidas providências para as autoridades cercearem estas práticas.

Ao que tudo indica, menos que reproduzir passivamente a voz das instituições e setores dirigentes, a posição assumida pelo jornal operário parece ter uma lógica subjacente. Esta lógica se configura ao longo de suas páginas, por meio da presença de uma proposta de valorização do trabalho e do trabalhador.

No jornal Vida Operária, a questão da valorização do trabalho e do trabalhador se apresenta em torno da ideia da produção de riquezas e da regeneração moral. No primeiro caso, afirma-se que

O trabalho [...] gera a electricidade, o telegrapho, que transmite os nossos pensamentos atravez dos continentes; [...] o vapor, que leva os transatlânticos por todos os mares desde o estreito de Behring ao cabo de Horn e da Islândia ao cabo da Boa Esperança.

\section{$[\ldots]$}

Para que haja progresso numa nação, para que adquira logar saliente entre as demais, a primeira condição é que seus cidadãos sejam amigos do trabalho.

A nação será o que seus filhos por seus actos, por seus trabalhos determinem; e o caracter do cidadão será o caracter da nação de que faz parte. ${ }^{41}$

Portanto, para o jornal, o papel desenvolvido pelo trabalho era o de construir os rumos do progresso, entendido como avanço tecnológico e material. No bojo desta construção aparecia o trabalhador, cuja função era desenvolver com afinco o seu papel social de gerar riquezas para sua região e/ou país. Daí que, para o periódico citado, o operário seja aquele que desenvolve atividades na terra "indo arrancar das adherências nativas o carvão que arde nas fornalhas candentes das usinas que condensam a electricidade"; é todo aquele que o "braço influe no dynamismo commercial, agrícola e industrial de um povo"; é aquele que "age construindo os tectos que nos abrigam, calçam as ruas que transitamos, aformoseam a cidade", ou seja, o que por meio de sua atividade produz

${ }^{41}$ Vida Operária, Manaus, n.14, 9 maio 1920. 
riquezas. ${ }^{42}$ Enfim, trabalho e trabalhador são definidos pelo jornal como instrumentos necessários para o desenvolvimento material de um povo.

Esta proposta de valorizar o trabalho e aquele que o desenvolve esteve presente, aliás, em outras regiões do país. Ângela de Castro Gomes, analisando o primeiro jornal socialista brasileiro - A Voz do Povo -, produzido no Rio de Janeiro nos anos iniciais do regime republicano, identificou uma proposta neste sentido. Segundo a autora, como a vida do trabalhador passou a ser alvo de discussões em várias esferas da sociedade, sobretudo nas instituições do governo, o jornal $A$ Voz do Povo, não se eximindo da questão, posicionou-se a respeito destacando dois elementos considerados como fundamentais para o trabalhador brasileiro: a revelação e o destaque de sua existência e a construção de uma identidade. No primeiro caso, "a operação implicava inverter os sinais pelos quais a categoria trabalho era identificada na sociedade de então". "Antes vistos como sinal de desgraça e atraso, eram agora encarados, tanto o trabalho como o trabalhador, como elementos de prosperidade, riqueza e progresso. Quanto ao segundo, a construção de uma identidade do trabalhador era necessária para unificar elementos diferenciados em torno de um programa de ação conjunta, uma vez que o "povo trabalhador era um conglomerado heterogêneo e disperso que precisava ganhar contornos para si mesmo e para a sociedade em geral". ${ }^{44}$ Ou seja, era preciso construir uma identidade social para o operário e dar-lhe lugar e presença no mercado, destacando o seu papel essencial na produção de riquezas.

Neste sentido, a ação do operário por meio do trabalho era fundamental para a sociedade em geral, na medida em que sua labuta diária estava diretamente associada ao desenvolvimento material de uma região, e mais amplamente, de um país.

No jornal Vida Operária, além disso, o trabalho foi encarado também como regenerador moral:

O trabalho encurta o tempo, enchuga as lágrimas, esquece os desgostos soffridos, evita crimes horríveis e dissipa os males. Elle é um bem: aqui, curando feridas

\footnotetext{
${ }^{42}$ Vida Operária, Manaus, n.5, 7 mar. 1920.

${ }^{43}$ GOMES, Ângela de Castro. A invenção do trabalhismo. 2. ed. Rio de Janeiro: Relume Dumará, 1994. p. 23.

44 Idem, p. 25.
} 
da alma; alli, evitando maos pensamentos e além fazendo a felicidade do que pratica. ${ }^{45}$

Neste fragmento extraído do jornal se observa, além de outros aspectos, que o trabalho "evita crimes horríveis". Aqui se está claramente diante da noção de vadiagem (do não trabalho) associada aos crimes. Também se está diante da ideia de que o ocioso contribui significativamente para a decadência de uma nação, como demonstra a citação a seguir:

[...] se seus filhos forem ociosos, entregando-se somente ao trabalho deshonesto como o roubo, ou por outras palavras não forem firmes e pontuaes no cumprimento dos seus deveres, a nação jamais conquistará o respeito e o progresso das demais. ${ }^{46}$

Diferentemente do jornal A Voz do Povo, analisado por Gomes, que tinha na sua proposta apenas a definição de trabalho como produtor de riquezas, no jornal Vida Operária as duas noções (trabalho como produtor de riquezas e regenerador moral) estavam presentes. Cabe destacar também que, nesta folha operária, o trabalho possuía uma outra dimensão, onde a exploração burguesa era sentida e denunciada; porém, no que tange à questão da valorização do trabalho e do trabalhador, esta dimensão assumia uma posição secundária, ao contrário de quando se enfatizava a luta política, em relação à qual a exploração do capital por meio do trabalho era explicitada.

O capitalismo na immensa brutalidade de tudo conquistar tem opprimido victimas indefezas e arrastado em turbilhões, pela ambição [...] e pelo direito da força.

O operariado esmagado pela prepotência sanguinária do capital há de saccudir o jugo em que se acha manietado, e proclamar debaixo da ordem aos quatro cantos os seus direitos conspurcados pelo próprio capital. ${ }^{47}$

\footnotetext{
${ }^{45}$ Vida Operária, Manaus, n.14, 9 maio 1920.

${ }^{46}$ Vida Operária, Manaus, n.15, 16 maio 1920.

${ }^{47}$ Vida Operária, Manaus, n. 4, 29 fev. 1920.
} 
Quanto ao trabalhador, foram identificados, nos textos do jornal, dois tipos: o honesto cumpridor de seu papel social e aquele que desenvolvia outros tipos de atividades, consideradas nocivas (como roubo, gatunagem, furto etc.). Deste modo, assim como as ações dos grupos politicamente dominantes, o jornal queria supostamente separar o trabalhador do não trabalhador, mas com um propósito bem definido: legitimar a luta política.

No interior da sociedade em que o jornal estava inserido, mostrar-se como trabalhador e cumpridor de seus deveres (afastado do jogo e do uso abusivo do álcool, considerados nocivos e responsáveis por prisões, já que eram delitos) era fundamental, uma vez que o simples fato de não possuir trabalho poderia significar uma visita ao xadrez (conforme o Código Penal Brasileiro e o Código de Posturas Municipal de Manaus, ambos de 1890). Esta forma de cercear a liberdade do indivíduo foi largamente utilizada nas décadas iniciais do século vinte e foi denominado de "prisão para averiguações" 48 (inserida nas ações policiais de caráter inibidor-repressivo).

Grande parte dos chamados "indesejáveis" era da classe trabalhadora que, nos anos iniciais da Primeira República, sofria com baixos salários, falta de assistência social, instabilidade no emprego e demais contingências que os colocavam constantemente à margem do processo produtivo. Geralmente ficavam desempregados, caíam na mendicância etc. A possibilidade de mudar esta situação se colocava como um desafio e a ação coletiva dos trabalhadores era clamada, pelas associações e sindicatos, como essencial para este fim. Porém, os movimentos coletivos dos trabalhadores - como protestos, passeatas e greves - podiam ser enquadrados como desordem pública e os envolvidos presos por isso. ${ }^{49}$ Neste jogo, o reconhecimento social e profissional (valorização do trabalho e do trabalhador) era extremamente fundamental para legitimar uma luta política em prol de melhores condições de vida e de trabalho.

\footnotetext{
${ }^{48}$ Prisão para averiguações "era o modelo de prisão por 24 horas, na qual o elemento era ainda considerado suspeito. Era o tempo exigido pela polícia para as investigações”. Ver: SANTOS JÚNIOR. Criminalidade e criminalização de práticas populares em Manaus. Op. cit. p. 157.

49 Conforme Bretas, no Rio de Janeiro várias manifestações de trabalhadores foram encaradas e enquadradas como ameaça à ordem pública (portanto caracterizadas como desordem e os envolvidos como desordeiros). Deste modo, eram passíveis de repressão policial. Ver: BRETAS, Marcos Luis. A guerra das ruas: povo e polícia na cidade do Rio de Janeiro. Rio de Janeiro: Arquivo Nacional, 1997. Em Manaus, ver: DIAS. A ilusão do fausto..., op. cit.
} 


\section{Considerações finais}

Observou-se que o processo de transformações do espaço urbano manauara e os mecanismos de implantação da ordem republicana e burguesa ocorridos em Manaus na última década do século XIX e nas duas iniciais do século $\mathrm{XX}$ trouxeram em seu bojo um conjunto de normas e regras de condutas tidas como "modernas", principalmente no que tange à organização do trabalho pelos grupos econômicos e políticos que compunham a elite manauara.

Os segmentos populares que caminhassem na contramão das regras e normas estabelecidas eram tidos como "indesejáveis" e como tais passíveis de punição por parte da legislação da época (principalmente o Código Penal e o Código de Posturas, como demonstrado). No caso dos operários, a viabilização de uma luta política significava apropriação de determinados elementos da ordem vigente, reelaborando-os para legitimar um conjunto de ações, como formação de associações operárias, partido operário, centro federativo etc.

Este processo passava pela construção e valorização do trabalho e do trabalhador, entendidos como elementos produtores de riquezas, indispensáveis à sociedade moderna e, portanto, merecedores de participação política (dentro das regras estabelecidas) e de melhoria das condições de trabalho e de vida. Era neste sentido que a proposta política contida no jornal Vida Operária caminhava para a criação de uma estrutura específica que articulasse os operários em associações ligadas a um centro federativo, por sua vez vinculado a um partido operário empenhado em lançar nomes para participar do processo político-eleitoral; tais representantes, uma vez eleitos, buscariam promover reformas sociais por meio da legislação. 